\title{
AKAP12 Regulates Human Blood-Retinal Barrier Formation by Downregulation of Hypoxia-Inducible Factor- $1 \alpha$
}

\author{
Yoon Kyung Choi, ${ }^{1 \star}$ Jeong Hun Kim, ${ }^{2 \star}$ Woo Jean Kim, ${ }^{4 \star}$ Hae Young Lee, ${ }^{1}$ Jeong Ae Park, ${ }^{5}$ Sae-Won Lee, ${ }^{3}$ \\ Dae-Kwan Yoon, ${ }^{1}$ Hyun Ho Kim, ${ }^{1}$ Hum Chung, ${ }^{2}$ Young Suk Yu, ${ }^{2}$ and Kyu-Won Kim ${ }^{1}$ \\ ${ }^{1}$ NeuroVascular Coordination Research Center, College of Pharmacy and Research Institute of Pharmaceutical Sciences, Seoul National University, Seoul \\ 151-742, Korea, ${ }^{2}$ Department of Ophthalmology, Seoul National University College of Medicine and Seoul Artificial Eye Center, ${ }^{3}$ Clinical Research Institute, \\ Seoul National University Hospital, Seoul 110-744, Korea, ${ }^{4}$ Neuroprotection Research Laboratory, Departments of Radiology and Neurology, Massachusetts \\ General Hospital, Harvard Medical School, Boston, Massachusetts 02115, and 5Department of Marine Biotechnology, College of Liberal Arts and Sciences, \\ Anyang University, Incheon 417-833, Korea
}

Many diseases of the eye such as retinoblastoma, diabetic retinopathy, and retinopathy of prematurity are associated with blood-retinal barrier (BRB) dysfunction. Identifying the factors that contribute to BRB formation during human eye development and maintenance could provide insights into such diseases. Here we show that A-kinase anchor protein 12 (AKAP12) induces BRB formation by increasing angiopoietin-1 and decreasing vascular endothelial growth factor (VEGF) levels in astrocytes. We reveal that AKAP12 downregulates the level of hypoxia-inducible factor- $1 \alpha$ (HIF- $1 \alpha$ ) protein by enhancing the interaction of HIF- $1 \alpha$ with pVHL (von Hippel-Lindau tumor suppressor protein) and PHD2 (prolyl hydroxylase 2). Conditioned media from AKAP12-overexpressing astrocytes induced barriergenesis by upregulating the expression of tight junction proteins in human retina microvascular endothelial cells (HRMECs). Compared with the retina during BRB maturation, AKAP12 expression in retinoblastoma patient tissue was markedly reduced whereas that of VEGF was increased. These findings suggest that AKAP12 may induce BRB formation through antiangiogenesis and barriergenesis in the developing human eye and that defects in this mechanism can lead to a loss of tight junction proteins and contribute to the development of retinal pathologies such as retinoblastoma.

Key words: A-kinase anchor protein 12 (AKAP12); barriergenesis; blood-retinal barrier (BRB); hypoxia-inducible factor-1 $\alpha$; retinoblastoma; retina

\section{Introduction}

The blood-retinal barrier (BRB) is a selective barrier of the eye composed of well differentiated microvessels. It plays an essential role in protecting neural tissues from toxic materials and in maintaining vision and neural function in the retina. The inner mature $\mathrm{BRB}$ is a complex system composed of highly specialized microvascular endothelial cells embedded in a basement membrane and surrounded by astrocytic end feet. In many in vitro models, astrocytes can induce barrier-like features when cocultured with cerebral brain endothelial cells (Stanness et al., 1996; Lee et al., 2003). A typical BRB-defect eye disease, retinoblastoma, is the most common intraocular malignant tumor in children. Retinoblastoma arises in the retina and is characterized by a lack of

\footnotetext{
Received Dec. 13, 2006; revised March 6, 2007; accepted March 12, 2007.

This work was supported by the Creative Research Initiatives (NeuroVascular Coordination Research Center) of the Ministry of Science and Technology. S.-W.L. is the recipient of a grant from the Korea Health 21 R\&D Project, Ministry of Health and Welfare (A062260). We thank Dr. G. Y. Koh (Korea Advanced Institute of Science and Technology, Daejeon, Korea) for providing COMP-Ang1. We also thank Dr. N. Joan Abbott (Wolfson Centre for Age Related Diseases, King's College, London, UK) for critical reading of this manuscript. We declare that we have no competing financial interests.

*Y.K.C., J.H.K., and W.J.K. contributed equally to this work.

Correspondence should be addressed to Dr. Kyu-Won Kim, NeuroVascular Coordination Research Center, College of Pharmacy, Seoul National University, Seoul 151-742, Republic of Korea. E-mail: qwonkim@plaza.snu.ac.kr. D01:10.1523/JNEUROSC1.5368-06.2007

Copyright $\odot 2007$ Society for Neuroscience $\quad 0270-6474 / 07 / 274472-10 \$ 15.00 / 0$
}

intermediate filaments (Kivela et al., 1986), leaky vessels, and high levels of vascular endothelial growth factor (VEGF). The expression of VEGF is mainly regulated by hypoxia-inducible factor-1 $\alpha$ (HIF-1 $\alpha$ ) (Ikeda et al., 1995; Ema et al., 1997; Maxwell et al., 1997), which is the most important transcriptional factor in hypoxia-induced angiogenesis (Semenza, 2003).

HIF-1 is composed of two subunits, an oxygen-sensitive HIF- $1 \alpha$ subunit and oxygen-insensitive HIF- $1 \beta$ subunit (Wang et al., 1995). HIF- $1 \alpha$ is stable under hypoxia, whereas it is unstable under normoxia. In normoxic conditions, the HIF- $1 \alpha$ subunit is rapidly degraded via the von Hippel-Lindau tumor suppressor protein (pVHL)-mediated ubiquitin-proteasome pathway (Salceda and Caro, 1997; Maxwell et al., 1999). The association of pVHL and HIF- $1 \alpha$ is triggered by prolyl hydroxylation within a polypeptide segment known as the oxygendependent degradation domain through the function of specific HIF-prolyl hydroxylases (PHDs) (Ivan et al., 2001; Jaakkola et al., 2001). In mammalian cells, three isoforms, PHD1, PHD2, and PHD3, have been identified and shown to hydroxylate in vitro the key proline residues of HIF- $1 \alpha$ (Epstein et al., 2001).

A-kinase anchor protein 12 (AKAP12) is a putative tumor suppressor that associates with protein kinase A (PKA) and protein kinase $\mathrm{C}(\mathrm{PKC})$ and serves as a scaffolding protein in signal transduction (Gelman et al., 2000; Gelman, 2002). AKAP12 ex- 


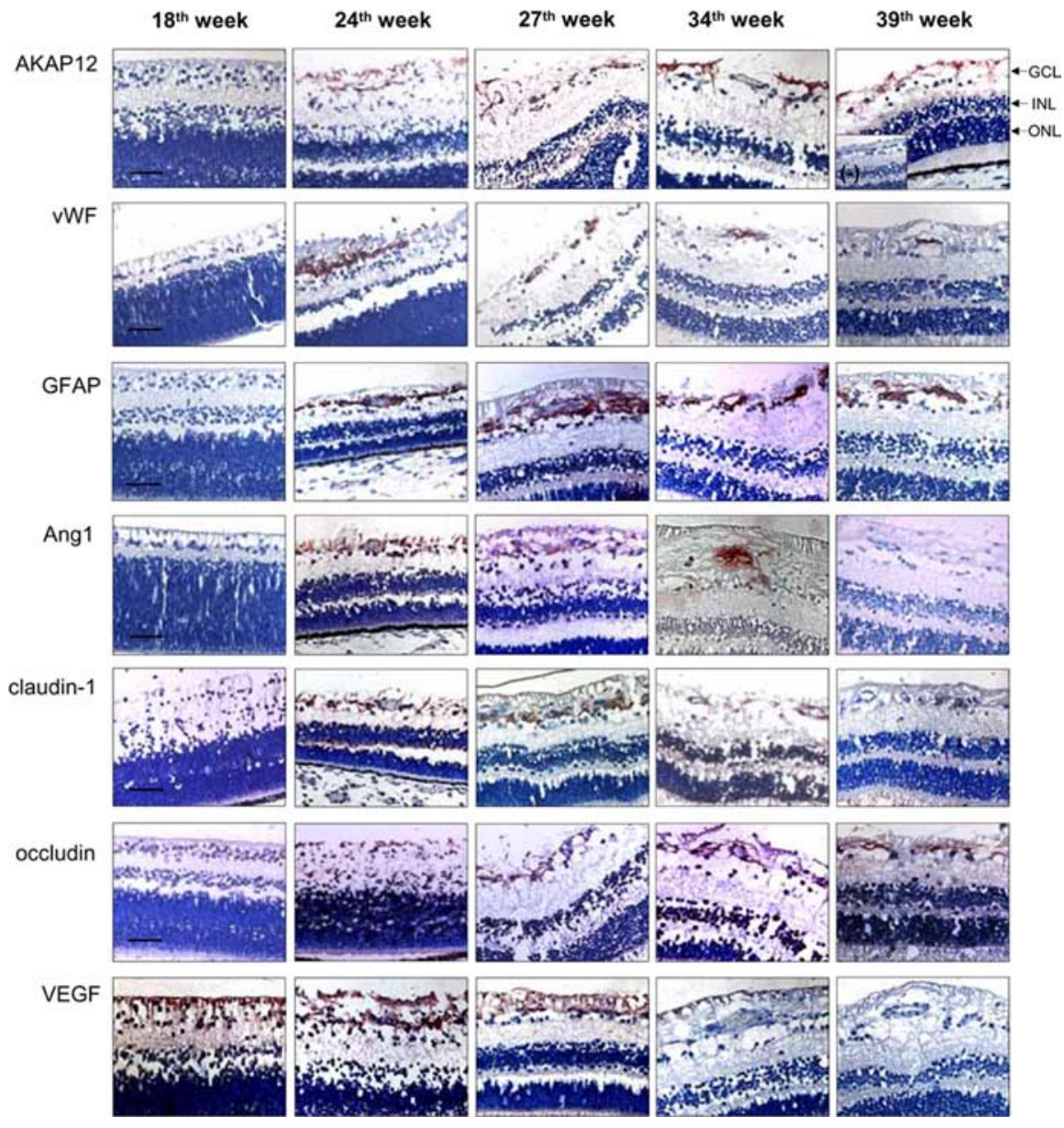

Figure 1. Immunohistochemical analysis of AKAP12, vWF, GFAP, Ang1, VEGF, and tight junction proteins in the developing human retina. Human fetal retinal sections were immunostained with antibodies to AKAP12, vWF, GFAP, Ang1, claudin-1, occludin, and VEGF (red). Nuclei were counterstained with hematoxylin and are seen in blue. The negative control was immunostained with normal rabbit lgG. GCL, ganglion cell layer; INL, inner nuclear layer; ONL, outer nuclear layer. Scale bar, $50 \mu \mathrm{m}$.

agnosed with retinoblastoma were obtained from the Seoul National University Children's Hospital. After nucleation, the eyeballs were fixed by immersion in Carnoy's solution for $2 \mathrm{~h}$ at room temperature. Each specimen was then dehydrated through a series of graded ethanol solutions and embedded in paraffin using standard techniques. Paraffin-embedded eyes were sectioned into $4 \mu \mathrm{m}$ sections, and sections were mounted on slides coated with $0.5 \%$ Elmer's glue for immunohistochemistry. Immunohistochemistry was performed using an InnoGenex (San Ramon, CA) immunohistochemistry kit. For quantitative analysis of immunostaining, Image-Pro Plus (Media Cybernetics, Bethesda, MD) was used.

Immunofluorescence staining. Cryosections were incubated with the indicated primary antibodies, followed by FITC-conjugated IgG and tetramethylrhodamine isothiocyanateconjugated IgG (Jackson ImmunoResearch, West Grove, PA) as secondary antibodies. Fluorescence immunostaining was evaluated using a confocal microscope (Bio-Rad, Hercules, CA). Human astrocyte cells were incubated overnight at $4^{\circ} \mathrm{C}$ with the indicated primary antibodies, followed by incubation with Alexa Fluor antibodies. Nuclei were stained using propidium iodide (Invitrogen, San Diego, CA). Images were obtained with an Axiovert M200 microscope (Zeiss, Oberkochen, Germany) and analyzed using Image-Pro Plus (Media Cybernetics).

Cell culture. Primary human brain astrocyte cells and dissociated normal human brain cortex tissue were purchased from the Applied Cell Biology Research Institute (Kirkland, WA). The CTX-TNA2 cell line, an established astrocytic cell line from the neonatal Sprague Dawley rat cerebral cortex, was purchased from the American Type Culture Collection (Manassas, VA). Primary human brain astrocyte cells,

pression is strongly suppressed in a variety of cancers (Xia et al., 2001; Liu et al., 2006). Src-suppressed C-kinase substrate (SSeCKS), the rodent ortholog of human AKAP12, is important for mouse brain homeostasis and regulating the formation of the blood-brain barrier (Lee et al., 2003). A recent report showed that SSeCKS/AKAP12 attenuates expression of angiogenic genes by suppressing Src-induced oncogenesis (Liu et al., 2006). However, it is not clear whether AKAP12 participates in antiangiogenesis and barriergenesis in the human retina. Moreover, the mechanism of barrier failure in the human eye is not well understood. In this study, we identified AKAP12 as a BRB-inducing factor in the developing human eye and provide evidence that aberrantly low expression of AKAP12 in retinoblastoma may lead to BRB dysfunction in this disease.

\section{Materials and Methods}

Tissue preparation and immunohistochemistry. A panel of human fetal eyes ranging every week from 18 to 40 weeks and five primarily enucleated eyes from retinoblastoma patients were used in this study. All samples were obtained with informed consent, institutional review board approval, and in accordance with the tenets of the Declaration of Helsinki. Fetal eyeballs were obtained from fetal autopsies at the Seoul National University Children's Hospital. The specimens selected were from fetuses that had no history of ophthalmologic congenital anomalies. Gestational age was determined from the last menstrual period of the mother and fetal measurements. Primarily enucleated eyeballs from patients di-
CTX-TNA2 cells, 786-O renal clear cell carcinoma cells, and HT1080 cells were cultured in DMEM supplemented with 10\% FBS (Invitrogen) and antibiotics. Human retina microvascular endothelial cells (HRMECs) were purchased from the Applied Cell Biology Research Institute and grown on attachment factor-coated plates in complete medium (Cell Systems, Kirkland, WA) or in M199 medium supplemented with $20 \%$ FBS, $3 \mathrm{ng} / \mathrm{ml}$ basic FGF (Millipore, Bedford, MA), and $10 \mathrm{U} / \mathrm{ml}$ heparin (Sigma, St. Louis, MO). For the analysis of HIF- $1 \alpha$ stability in 786-O renal clear cell carcinoma cells, cells were transfected with a plasmid encoding myc-pVHL and selected using G418 (Invitrogen; or BRL, Bethesda, MD). For hypoxia experiments, astrocytes were incubated in a hypoxic chamber (Forma Scientific, San Bruno, CA) that maintained the cells under low oxygen tension $\left(5 \% \mathrm{CO}_{2}\right.$ with $1 \% \mathrm{O}_{2}$, balanced with $\left.\mathrm{N}_{2}\right)$.

Luciferase assay. Astrocytes were transfected with a plasmid for Akap12, the hypoxia-response element (HRE) luciferase reporter vector, or the VEGF promoter vector (pGL3-mVEGF), pBOS-hHIF and pCMV$\beta$-gal. Luciferase assays were performed using the Luciferase Assay System (Promega, Madison, WI), and analyzed using a luminometer (Turner Designs, Sunnyvale, CA). Luciferase-generated light units were normalized to $\beta$-galactosidase activity.

Western blot analysis. Cellular protein from transfected astrocytes or conditioned medium (CM)-treated HRMECs and secreted proteins in $\mathrm{CM}$ were analyzed by Western blot. Western blot analysis was performed as described previously (Moon et al., 2004). We used antibodies specific for AKAP12 (a gift from Dr. I. H. Gelman, Roswell Park Cancer Institute, Buffalo, NY; or Santa Cruz Biotechnology, Santa Cruz, CA); HIF-1 $\alpha$ (Novus Biologicals, Littleton, CO; or BD Pharmingen, San Diego, CA); 
VEGF (Santa Cruz Biotechnology); zonula occludens 1 (ZO-1), claudin-3, and claudin-5 (Zymed, San Francisco, CA); claudin-1 (Zymed; or Abcam, Cambridge, UK); occludin (Santa Cruz Biotechnology or Zymed); angiopoietin-1 (Ang1; R \& D Systems, Minneapolis, MN; or Santa Cruz Biotechnology); pVHL (BD PharMingen); PHD2 (Novus Biologicals); $\beta$-actin (Sigma); $\alpha$-tubulin (BioGenex, San Ramon, CA). Recombinant VEGF $_{165}$ was purchased from R \& D Systems, and COMP-Ang1 was a generous gift from Dr. G. Y. Koh (Korea Advanced Institute of Science and Technology, Daejeon, Korea). L-mimosine (Mim) and ethyl 3,4-dihydroxybenzoate (DHB) were purchased from Sigma and used at a $300 \mu \mathrm{M}$ concentration. MG132, a proteasome inhibitor, was purchased from Calbiochem (La Jolla, CA). Ponceau S solution was purchased from Sigma.

Immunoprecipitation. Cellular protein $(300$ $\mu \mathrm{g})$ from transfected astrocytes was incubated with the indicated antibodies and protein $\mathrm{A}$ or G Sepharose in TEG buffer (20 mm Tris-Cl, pH 7.4, 1 mm EDTA, 10\% glycerol, and $1 \mathrm{~mm}$ dithiothreitol containing $150 \mathrm{~mm} \mathrm{NaCl}$ and $0.1 \%$ Triton $\mathrm{X}-100$ ) at $4^{\circ} \mathrm{C}$ for $16 \mathrm{~h}$ with constant rotation. Sepharose pellets were collected by centrifugation and washed three times with supplemented TEG buffer. Immunoprecipitates were analyzed by SDS-PAGE, followed by Western blot using the indicated antibodies.

Transient transfection and CM preparation. The full-length rat Akap12 cDNA was subcloned into the pcDNA3. Transient transfections were performed using Lipofectamine Plus reagent (Invitrogen). For preparation of $\mathrm{CM}$ for Western blot analysis, FBS-free medium from transfected cells was collected and concentrated through an Ultra-4 filter device (Millipore, Beverly, MA). We also used trichloroacetic acid precipitation, as described by Sambrook and Russel (2001). For preparation of CM for treating HRMECs, medium from transfected astrocytes was changed into M199 medium containing $1 \%$ FBS for $24 \mathrm{~h}$, collected and filtered through a $0.22 \mu \mathrm{m}$ pore size membrane (Millipore), and then concentrated four times using centrifugal filters (Millipore).

Permeability assay. Permeability across the endothelial cell monolayer was measured by using type I collagen-coated transwell units (6.5 $\mathrm{mm}$ diameter, $3.0 \mu \mathrm{m}$ pore size polycarbonate filter; Corning, Corning, NY; or Costar, Cambridge, MA). After HRMECs become confluent, CM was treated for $24 \mathrm{~h}$. Permeability was measured by adding $0.1 \mathrm{mg}$ of Rhodamine B isothiocyanate (RITC)-labeled dextran (molecular weight, $\sim 10,000)$ per milliliter to the upper chamber. After incubation for $15 \mathrm{~min}, 100 \mu \mathrm{l}$ of sample from the lower compartment was diluted with $100 \mu \mathrm{l}$ of PBS and measured for fluorescence at $635 \mathrm{~nm}$ when excited at $540 \mathrm{~nm}$ with a spectrophotometer (Tecan SpectraFluor; Tecan Durham, NC).

RNA interference. Astrocytes were grown to $80 \%$ confluence, and small interfering RNAs (siRNAs) $(50 \mu \mathrm{M})$ were transfected into the cells using Lipofectamine Plus or Lipofectamine2000 reagent (Invitrogen). All transfections were performed according to the manufacturer's instructions. siRNAs and the control nonsilencing RNAs were designed by Dharmacon (Lafayette, CO). The human Akap12

B
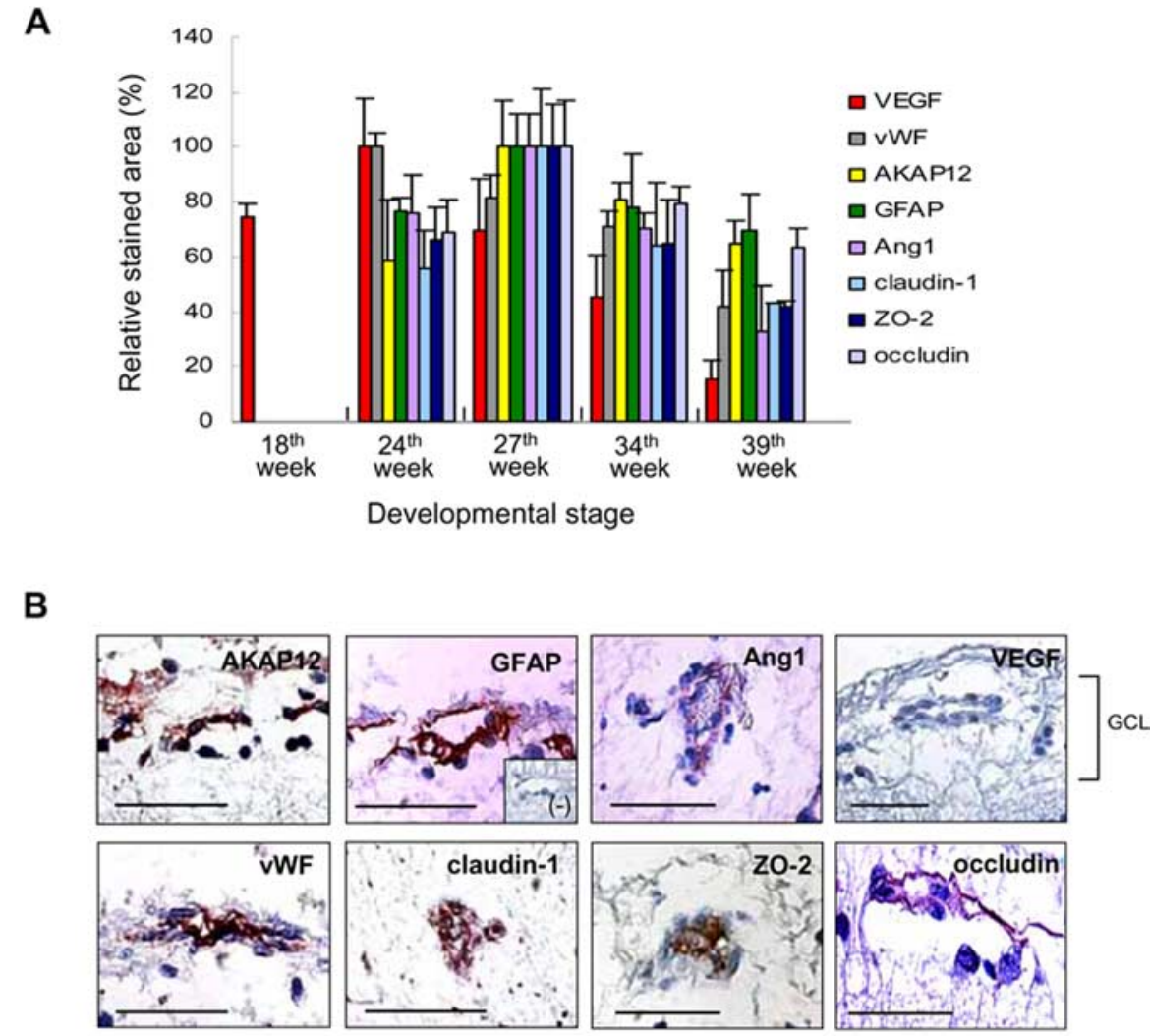

2. Immunohistochemical analysis in the developing human retina. $A$, Immunoreactivity of the indicated factors was GFAP, Ang1, claudin-1, Z0-2, and occludin) or at 24 weeks (VEGF and vWF). At least three different tissues were used for each stage from 18 to 40 weeks. $\boldsymbol{B}$, Immunohistochemical analysis of the expression of AKAP12, GFAP, Ang1, VEGF, vWF, and the tight immunofluorescence staining for AKAP12 (red) and GFAP (green) at 34 weeks of fetal retinal tissue. Colocalization of the two proteins is seen as yellow fluorescence. Scale bars, $50 \mu \mathrm{m}$.

target sequence used was as follows: 5'-AGACGGATGTAGTGTTGAA-3'. The human PHD2 target sequence used was as follows: 5'-CTTCAGATTCGGTCGGTAAAG-3'. The human HIF- $1 \alpha$ target sequence used was as follows: 5'-CTGGACACAGTGTGTTTGA-3'.

Reverse transcription PCR. Total RNA was isolated from the indicated cells using Trizol reagent (Invitrogen). Reverse-transcription (RT)-PCR analysis was performed as described previously (Lee et al., 2001a). The following sets of primers were used: rat Akap12, 5'-GCCAGTCCTGACACTTG-3', 5'-TGAGCCCATGCCTCCAGAA-3'; VEGF, 5'GAGAATTCGGCCTCCGAAACCATGAACTTTCTGT-3' (forward) and 5'-GAGCATGCCCTCCTGCCCGGCTCACCGC-3' (reverse); human HIF-1 $\alpha$ 5'-AGTCGGACAGCCTCAC-3' (forward) and 5'TGCTGCCTTGTATAGGA-3' (reverse); human Ang1, 5'-GAAGGGAACCGAGCCTATTC-3' (forward) and 5'-GGGCACATTTGCA- 
A
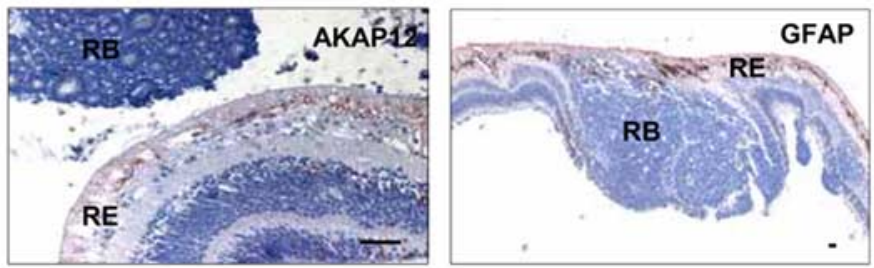

B

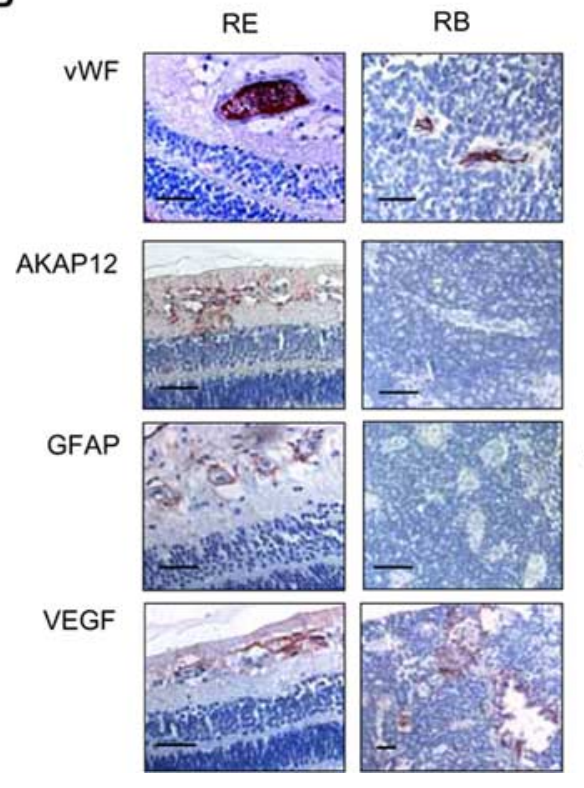

RE

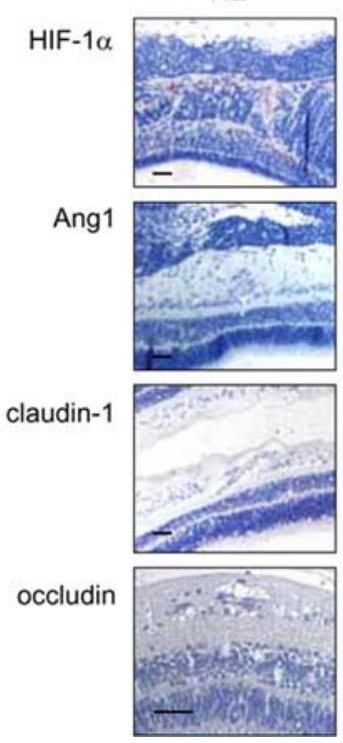

Figure 3. Immunohistochemical analysis in the retinoblastoma tissues. $A$, Immunohistochemical analysis of AKAP12 and GFAP in retinoblastoma tissue. Retina (RE), Area of the retina outside of the tumor; retinoblastoma (RB), tumor region. $\boldsymbol{B}$, Immunohistochemical analysis of vWF, AKAP12, GFAP, VEGF, HIF-1 $\alpha$, Ang1, claudin-1, and occludin expression in the RE (left) and RB (right) of retinoblastoma tissues. Scale bars, $50 \mu \mathrm{m}$.

CATACAG-3' (reverse). PCR products were analyzed on 1.2\% agarose gels and the gels were digitally imaged.

Data analysis and statistics. Quantification of band intensity was analyzed using ImageJ (http://rsb.info.nih.gov/ij/) and normalized to the density of the $\beta$-actin or ponceau staining band. All data are presented as mean \pm SD changed into relative percentage. The highest intensity of each protein level was set to $100 \%$. Statistical comparisons between groups were done using Student's test. $p<0.05$ was considered statistically significant.

\section{Results}

\section{AKAP12 immunoreactivity in vivo during human} eye development

To examine the changes in AKAP12 immunoreactivity in vivo during human eye development, we used immunohistochemistry to quantitatively analyze immunostained retinas every week from 18 to 40 weeks of development. AKAP12 expression was not detected before 22 weeks but was clearly detectable from 22 to 40 weeks. The highest AKAP12 expression was detected during 26-34 weeks, which is the period of vascular maturation in the eye (Figs. 1, 2A). Moreover, AKAP12-positive immunostaining was present surrounding blood vessels in the tissues. Immunopositive staining of von Willebrand factor (vWF), a vessel marker, was detected at 24 weeks and maintained throughout human retinal development. The staining pattern of glial fibrillary acidic protein (GFAP), an astrocyte-specific marker, and Ang1 also coincided spatiotemporally with that of AKAP12 (Figs. 1, 2A).

RB

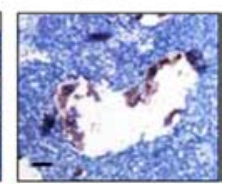

Ang1 acts as a key factor in vessel maturation by increasing the expression of tight junction proteins in endothelial cells (Lee et al., 2003; Hori et al., 2004). We found that the expression pattern of tight junction proteins such as claudin-1, ZO-2, and occludin was similar to that of Ang1 and AKAP12 during human retinal development (Figs. 1, 2A). Furthermore, we determined VEGF expression at the same stages to assess retina angiogenesis and the oxygen state (Lee et al., 2001b; Sandercoe et al., 2003; Werdich et al., 2004). VEGF immunoreactivity increased during the early stages of fetal eye development, peaked at 24 weeks during active angiogenesis, and declined thereafter (Figs. 1, $2 A)$. Thus, the expression of VEGF varied inversely with that of AKAP12, because the VEGF-stained area remarkably decreased during BRB maturation, whereas the areas stained by AKAP12 increased markedly.

To identify the locations of AKAP12, Ang1, and tight junction proteins, we examined their pattern of expression in tissues surrounding retinal vessels at 34 weeks. AKAP12 appeared to localize in astrocytes, which were identified by GFAPpositive immunostaining (Fig. $2 \mathrm{~B}$ ). Moreover, coexpression analysis at 34 weeks in retina tissue revealed that AKAP12 immunofluorescence overlapped with that of GFAP (Fig. 2C), indicating that AKAP12 is expressed in astrocytes in the fetal retina. As shown in Figure $2 B$, Ang1 expression was detected in perivascular regions, whereas VEGF expression was not detected. When vessels were immunostained for vWF, we found that immunopositive staining of claudin-1, ZO-2, and occludin coincided spatiotemporally with that of vWF (Fig. $2 B$ ). These staining patterns indicate that AKAP12-expressing astrocytes localize close to retinal vessels and that AKAP12 may induce the formation of tight junctions in endothelial cells, thus stabilizing the BRB structure.

\section{AKAP12 immunoreactivity in retinoblastoma tissues}

To extend our findings to human retinal pathology, we conducted fluorescein angiograms of retinoblastoma tissues and examined expression of AKAP12, GFAP, and tight junction proteins in the tumor and in the surrounding tissues (Fig. 3). The angiograms showed leakage of fluorescein from the tumor vessels (data not shown). Interestingly, AKAP12- and GFAP-positive immunostaining was restricted to areas of the retina outside of the tumor and was not detected within the tumor (Fig. 3A), although many blood vessels were distributed all over the tumor, as revealed by strong vWF-positive staining (Fig. 3B). AKAP12 immunoreactivity in retinoblastoma tissue coincided with that of GFAP, with both exhibiting weak and irregular distribution patterns along the vessels of the retina (Fig. 3). In contrast, VEGF expression was increased both within the region of the tumor and in the retinal region outside of the tumor. HIF- $1 \alpha$ was weakly detected in the transformed region from retina to tumor and 
strongly detected in the tumor region (Fig. 3B). However, Ang1, claudin-1, and occludin expression was completely absent in the retinoblastoma tissue and in the surrounding retina (Fig. 3B), and the level of ZO-2 was not detected in retinoblastoma tissues (data not shown). These results suggest that reduced expression of AKAP12 and Ang1 and increased expression of VEGF and HIF- $1 \alpha$ are closely related to the disappearance of tight junctions and the leakage of retinoblastoma blood vessels.

\section{AKAP12 regulates the expression of Ang1 and VEGF}

The natural generation of hypoxia in the developing retina induces key events in the formation of blood vessels (West et al., 2005). Exposure of astrocytes to the resulting elevated oxygen levels (reoxygenation) may contribute to the maturation of the retinal vessels. AKAP12 level was decreased during hypoxia and increased during reoxygenation in human astrocytes (Fig. 4A). Also during reoxygenation, the level of Ang1 and VEGF in CM was upregulated and downregulated, respectively, compared with that of the hypoxic condition (Fig. 4A), indicating that there is a counteracting mechanism for the regulation of Ang1 and VEGF that may be influenced by AKAP12. To investigate the role of AKAP12 in BRB differentiation, we transfected an siRNA targeting Akap12 (siAkap12) into human astrocytes. Inhibition of AKAP12 expression by siAkap12 resulted in a decrease in the expression of Ang1 and an increase in the level of VEGF in CM (Fig. 4B). Transfection of Akap12 into human astrocytes increased Ang1 levels in CM under hypoxic conditions (Fig. 4C). These results show that AKAP12 influences the secretion of an angiogenic factor, VEGF, and vessel remodeling factor, Ang1, in response to oxygen tension.

\section{Ang1 mediates effect of AKAP12 on tight junction proteins}

To investigate whether AKAP12 induces inner BRB formation, we examined the effect of CM from Akap12-transfected astrocytes (AKAP-CM) on the expression of tight junction proteins, which are important in maintaining barrier function (Morcos et al., 2001; Engelhardt, 2003; Abbott et al., 2006) in HRMECs. AKAP-CM strongly increased the expression of ZO-1, ZO-2, claudin-1, claudin-3, claudin-5, and occludin in HRMECs (Fig. $5 A$ ). These effects were blocked when the AKAP12-CM was pretreated with an anti-Ang1 antibody. Using the passage of RITCdextran through monolayers of HRMECs as a measure of permeability, we found that AKAP-CM significantly reduced vascular permeability, whereas Ang1-neutralized AKAP-CM did not (Fig. $5 B)$. These results indicate that the expression of AKAP12 in astrocytes may induce the barrier function between endothelial cells in part through Ang1. To explore the roles of Ang1 and VEGF in BRB formation, we treated HRMECs with recombinant VEGF $_{165}$ and a chimeric form of Ang1 in which the N-terminal portion of Ang1 was replaced with the short-coiled coil domain of cartilage oligomeric matrix protein (COMP-Ang1). COMPAng1 is soluble and more potent than native Ang1 in phosphorylating the Tie2 receptor and Akt in endothelial cells (Cho et al., 2004). COMP-Ang1 treatment of HRMECs induced a greater increase in the expression of ZO-1 and ZO-2, whereas VEGF treatment decreased the levels of ZO-1 and ZO-2 (Fig. 5C). Because the inhibition of AKAP12 expression by siAkap12 resulted in a decrease of Ang1 and an increase of VEGF in CM (Fig. 4B), we investigated whether siAkap12-transfected CM (siAkap-CM) from astrocytes influences the distribution of $\mathrm{ZO}-1, \mathrm{ZO}-2$, and claudin-1 in HRMECs. ZO-1, ZO-2, and claudin-1 immunofluorescence incubated with siAkap-CM was significantly decreased, exhibiting weak and discontinuous distribution patterns
A
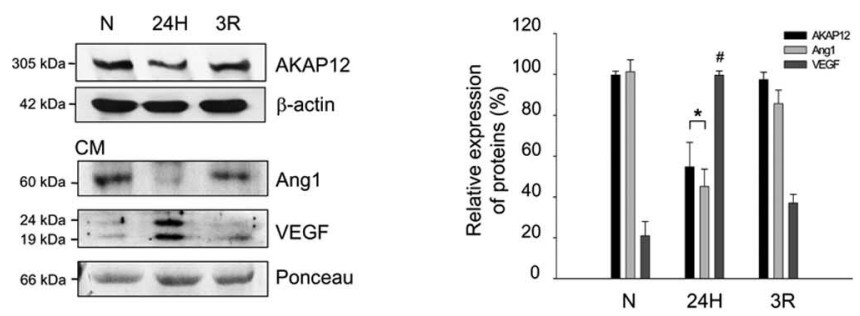

\section{B}
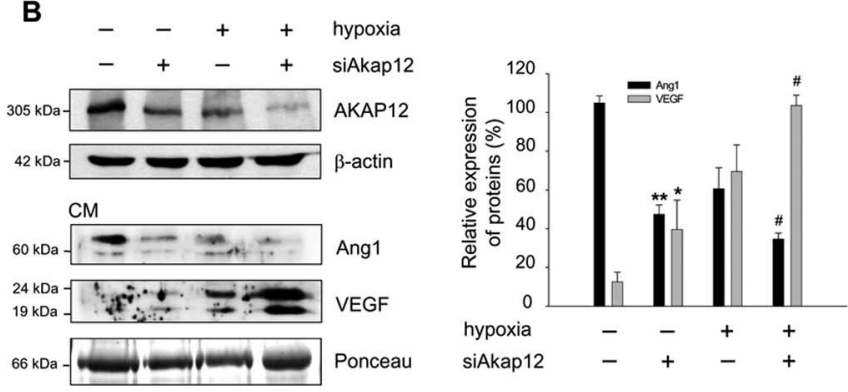

\section{C}
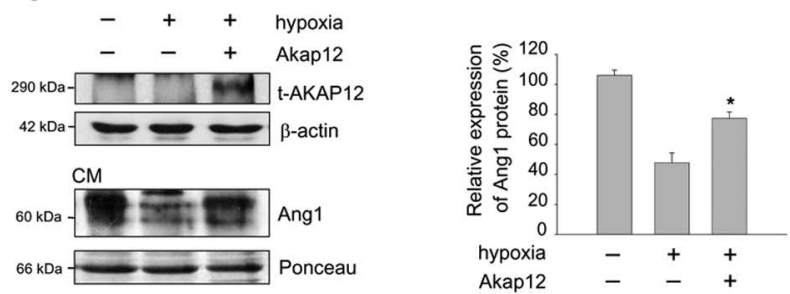

Figure 4. AKAP12 differentially regulates the expression of Ang1 and VEGF. $A$, Human astrocytes were exposed to normoxia (N), $24 \mathrm{~h}$ of hypoxia (24H), or $24 \mathrm{~h}$ of hypoxia followed by $3 \mathrm{~h}$ of reoxygenation (3R). AKAP12 in cell lysates and Ang1 and VEGF in CM were analyzed by Western blot under the indicated levels of oxygen tension. The quantification of the immunoblot from three independent experiments is shown on the right. The expression of AKAP12 and Ang1 under normoxia was set to $100 \%$ and the VEGF expression under hypoxia was set to $100 \%$. ${ }^{*} p<0.05$ compared with normoxic and reoxygenation conditions; ${ }^{\#} p<0.01$ compared with normoxic and reoxygenation conditions. B, Human astrocytes were transfected with siAkap12, incubated for $12 \mathrm{~h}$, and then exposed to $24 \mathrm{~h}$ of normoxia or hypoxia. The quantification of the immunoblot from four independent experiments is shown on the right. Ang1 expression was set to $100 \%$ in the control under normoxia, and VEGF expression was set to $100 \%$ in siAkap $12-$ transfected hypoxic condition. ${ }^{* *} p<0.001$ compared with control in normoxic condition; ${ }^{*} p<0.05$ compared with control in normoxic condition; ${ }^{*} p<0.05$ compared with control in hypoxic condition. C, Rat Akap12 was transfected into human astrocytes, incubated for $12 \mathrm{~h}$, then exposed to $24 \mathrm{~h}$ of normoxia or hypoxia. Levels of transfected AKAP12 protein (t-AKAP12) in whole-cell lysate and Ang1 in CM were analyzed by Western blot. The quantification of the immunoblot from three independent experiments is shown on the right. The expression under normoxia was set to $100 \%{ }^{*} p<0.05$ compared with mock-transfected control in hypoxic condition. $\beta$-actin and Ponceau red staining served as the controls for total protein levels.

along the cell-cell contact in HRMECs (Fig. 5D). The expression of claudin-5 and occludin, the main structural transmembrane component of tight junction proteins (Furuse et al., 1994; Nitta et al., 2003), was also significantly reduced (Fig. $5 D$ ) and the vascular permeability was remarkably $(p<0.01)$ increased at the same conditions (data not shown). These results suggest that reciprocal regulation of the levels of Ang1 and VEGF by AKAP12 may play a major role in inducing vessel tightness during BRB maturation. Next, we investigated whether HIF- $1 \alpha$ is involved in the regulation of Ang1 expression because the expression of Ang1 was tightly regulated by oxygen tension in astrocytes (Fig. 4A). To examine the effect of HIF- $1 \alpha$ on Ang1 expression, siRNA targeting HIF- $1 \alpha$ (siHIF- $1 \alpha)$ was transfected into human astrocytes. 
A

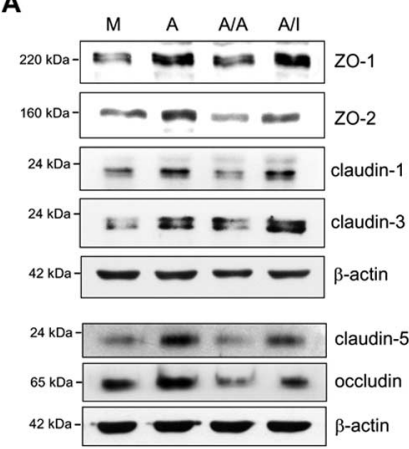

B

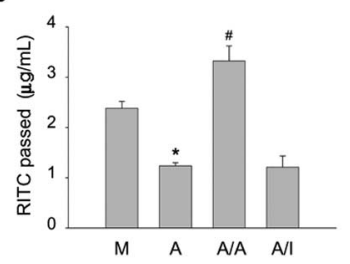

C

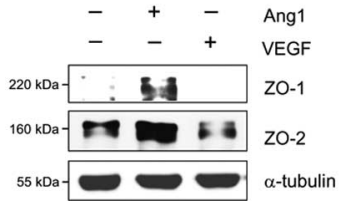

D
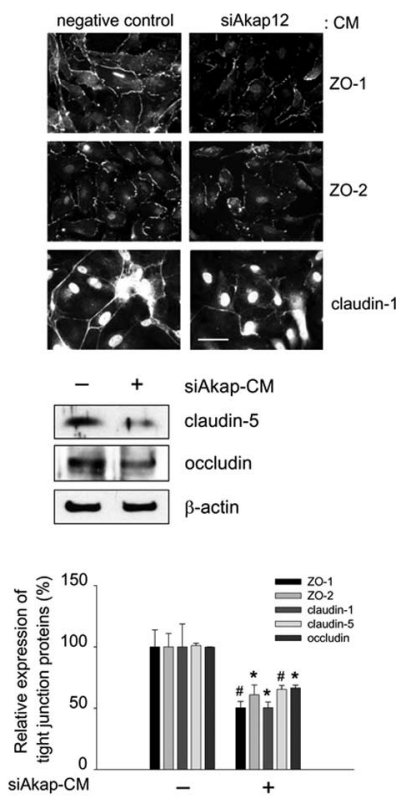

A
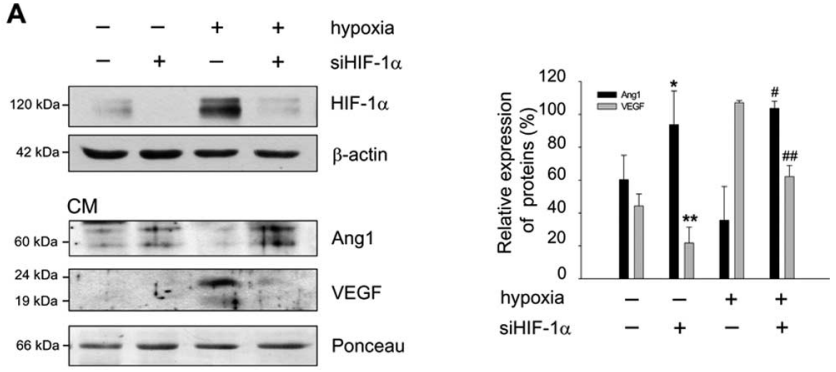

B $\quad-\quad+\quad+$ hypoxia -+-+ siHIF-1 $1 \alpha$

TT-PCR

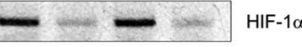

$-\infty$ Ang1

Figure 6. HIF-1 $\alpha$ is involved in the regulation of Ang1 expression. $A$, Human astrocytes were transfected with siHIF- $1 \alpha$, incubated for $12 \mathrm{~h}$, then exposed to $24 \mathrm{~h}$ of normoxia or hypoxia. HIF- $1 \alpha$ in cell lysates, and Ang1 and VEGF in CM were analyzed by Western blot. The quantification of the immunoblot from three independent experiments is shown on the right. Ang1 expression was set to $100 \%$ in siHIF- $1 \alpha$-transfected hypoxic condition, and VEGF expression was set to $100 \%$ in the control under hypoxia. ${ }^{*} p<0.05$ compared with control in normoxia; ${ }^{* *} p<0.01$ compared with control in normoxia; ${ }^{*}<0.05$ compared with control in hypoxia; $\# p<0.01$ compared with control in hypoxia. $\beta$-actin and Ponceau red staining served as the controls for total protein levels. $\boldsymbol{B}$, Astrocytes were transfected with siHIF- $1 \alpha$, and mRNA levels of HIF-1 $\alpha$, Ang1, and VEGF were analyzed by RT-PCR.

Figure 5. AKAP12 regulates the expression of tight junction proteins, which is mediated by Ang1. A, Expression of Z0-1, Z0-2, claudin-1, claudin-3, claudin-5, and occludin in HRMECS treated with CM from Akap12-transfected astrocytes was analyzed by Western blot. M, MockCM; A, AKAP12-CM; A/A, AKAP12-CM pretreated with anti-Ang1 antibody; A/I, AKAP12-CM pretreated with control lgG. Representative Western blots are shown $(n=3)$. B, RITC-dextran passage was analyzed for vascular permeability in HRMECs at the same conditions as in $A .{ }^{*} p<$ 0.01 compared with mock-CM; ${ }^{*} p<0.01$ compared with AKAP12-CM. C, Expression of Z0-1 and Z0-2 in HRMECs treated with $10 \mathrm{ng} / \mathrm{ml} \mathrm{VEGF}_{165}$ and $100 \mathrm{ng} / \mathrm{ml}$ COMP-Ang 1 for $6 \mathrm{~h}$ was analyzed by Western blot $(n=3)$. D. Top, Expression of Z0-1, Z0-2, and claudin- 1 in HRMECs treated with negative control or siAkap12-transfected CM (siAkap-CM) from astrocytes was analyzed by immunofluorescence staining. Middle, The expression of claudin- 5 and occludin was analyzed by Western blot. Bottom, The quantification of the intensity from three independent experiments is shown. The expression was set to $100 \%$ in CM from negative controltransfected astrocytes. ${ }^{*} p<0.05$ compared with control; ${ }^{\sharp} p<0.001$ compared with control. Scale bar, $50 \mu \mathrm{m}$.

We found that siHIF-1 $\alpha$ increased the level of Ang1 in CM from transfected cells and decreased the level of VEGF (Fig. 6A). In addition, the level of Ang1 mRNA was also upregulated, whereas VEGF mRNA was downregulated in siHIF- $1 \alpha$-transfected cells (Fig. $6 B$ ). These results suggest that secretion of Ang1 and VEGF induced by astrocytic AKAP12 is mediated in part by HIF- $1 \alpha$.

\section{Negative regulation of HIF- $1 \alpha$ stability by AKAP12}

AKAP12 and HIF- $1 \alpha$ were reciprocally regulated by oxygen tension (Fig. 7A). Therefore, we examined the effect of AKAP12 on HIF- $1 \alpha$ and found that overexpression of AKAP12 in human astrocytes significantly decreased the level of HIF- $1 \alpha$ protein in cell lysates (Fig. $7 B$ ) but did not decrease HIF- $1 \alpha$ mRNA level (Fig. 7C). We also found that transfection with siAkap12 markedly induced HIF- $1 \alpha$ level, as assessed by Western blot, under both normoxic and hypoxic conditions (Fig. 7D). Moreover, an enhanced level of HIF- $1 \alpha$ after transfection of siAkap12 was clearly detected in the nucleus by immunocytochemistry (Fig. $7 E)$. Thus, inhibition of AKAP12 through siAkap12 transfection

significantly increased the level of HIF- $1 \alpha$ protein in astrocytes, whereas overexpression of AKAP12 diminished HIF- $1 \alpha$ protein level.

\section{Inhibition of HIF-1- and VEGF-mediated transactivation by AKAP12}

Next, we performed a luciferase reporter assay and found that overexpression of AKAP12 inhibited the transcriptional activity of HIF- $1 \alpha$ under hypoxic condition, suggesting that AKAP12 negatively regulates the hypoxia-inducible transcriptional activity of HIF-1 (Fig. 8A). AKAP12 also significantly downregulated VEGF secretion, mRNA level, and transcriptional activity (Fig. $8 B$ ). Thus, these results strongly suggest that AKAP12 functions as a negative regulator of HIF- $1 \alpha$ and VEGF.

\section{AKAP12 decreases the stability of HIF- $1 \alpha$ by increasing its association with $\mathrm{pVHL}$}

Overexpression of AKAP12 downregulated HIF- $1 \alpha$ at the protein level but did not affect HIF- $1 \alpha$ mRNA level (Fig. $7 B, C$ ), suggesting that regulation of HIF- $1 \alpha$ by AKAP12 was not resulting from reduced transcription of the gene encoding HIF- $1 \alpha$. Rather, our results indicate that the stability of the HIF- $1 \alpha$ was reduced by AKAP12. We next examined whether AKAP12 plays a role in the association of HIF- $1 \alpha$ and pVHL, which leads to ubiquitination and degradation of HIF- $1 \alpha$. Interestingly, the interaction of HIF- $1 \alpha$ and $\mathrm{pVHL}$ was potently increased by expression of AKAP12 and decreased by siAkap12 under both normoxic and hypoxic conditions (Fig. 9A,B). Moreover, HIF- $1 \alpha$ protein and mRNA levels were unaffected, and VEGF mRNA level was also not changed by AKAP12 in pVHL-deficient 786-O renal clear cell carcinoma cells (Fig. 9C). In these cells, HIF-1 $\alpha$ protein level was unaffected by siAkap12 (Fig. 9D). In 786-O cells that stably expressed pVHL, however, HIF-1 $\alpha$ protein level was upregulated after transfection of 
siAkap12 (Fig. 9D), indicating that the effect of AKAP12 in HIF- $1 \alpha$ downregulation is pVHL-dependent.

AKAP12 decreases the stability of HIF$1 \alpha$ by increasing its association with PHD2

The VHL E3 ubiquitin ligase complex associates with hydroxylated proline residues and targets HIF- $1 \alpha$ for proteasomal degradation (Salceda and Caro, 1997; Maxwell et al., 1999; Ivan et al., 2001; Jaakkola et al., 2001). Because the silencing of PHD2 by transfection of siRNA is sufficient to stabilize and activate HIF- $1 \alpha$ under normoxic conditions in various human cells (Berra et al., 2003; Appelhoff et al., 2004), we next investigated whether the interaction of HIF- $1 \alpha$ and PHD2 was regulated by AKAP12. The interaction of HIF- $1 \alpha$ and PHD2 was potently increased by expression of AKAP12, and decreased by siAkap12, under both normoxic and hypoxic conditions (Fig. 10A,B). Recovery from AKAP12-induced destabilization of HIF- $1 \alpha$ was observed after transfection of siRNA targeting PHD2 in astrocytes (Fig. $10 C)$ and after treatment with the PHD inhibitors such as Mim or DHB in HT1080 cells (Fig. 10D). These results suggest that AKAP12 is a key regulatory protein in the degradation of HIF- $1 \alpha$ through PHD2mediated proline hydroxylation and the pVHL ubiquitination complex.

\section{Discussion}

In the present study, we investigated the distribution of AKAP12, Ang1, VEGF, and tight junction proteins in in vivo human eye development (Fig. 1). We analyzed immunostained retinas every week from 18 to 40 weeks of development. On stillunvascularized retina, VEGF expression was strongly detected (Figs. 1, 2A), which may be caused by the increasing metabolism of retinal neurons (Stone et al., 1995). AKAP12 expression was clearly detected from 23 to 40 weeks, and the staining pattern was coincided spatiotemporally with that of GFAP (Figs. 1,2), suggesting that AKAP12 is expressed in astrocytes. The highest expression of AKAP12, Ang1, and tight junction proteins was detected from 26 to 34 weeks (Figs. 1, 2A), which is the vascular maturation period in the human eye. Thus, the expression of VEGF varied inversely with that of AKAP12, because the VEGF-stained area remarkably decreased during BRB maturation, whereas the areas stained by AKAP12, Ang1, and tight junction proteins increased markedly.

Astrocytes play a key role in the development of retinal vessels by detecting hypoxia in developing retina and by stimulating the expression of hypoxia-induced angiogenic factors such as HIF- $1 \alpha$ and VEGF to induce new vessel formation (Stone et al., 1995; Jain et al., 1998; Madan et al., 2002). Oxygen delivered by the retinal vasculature is an important factor in the cessation of
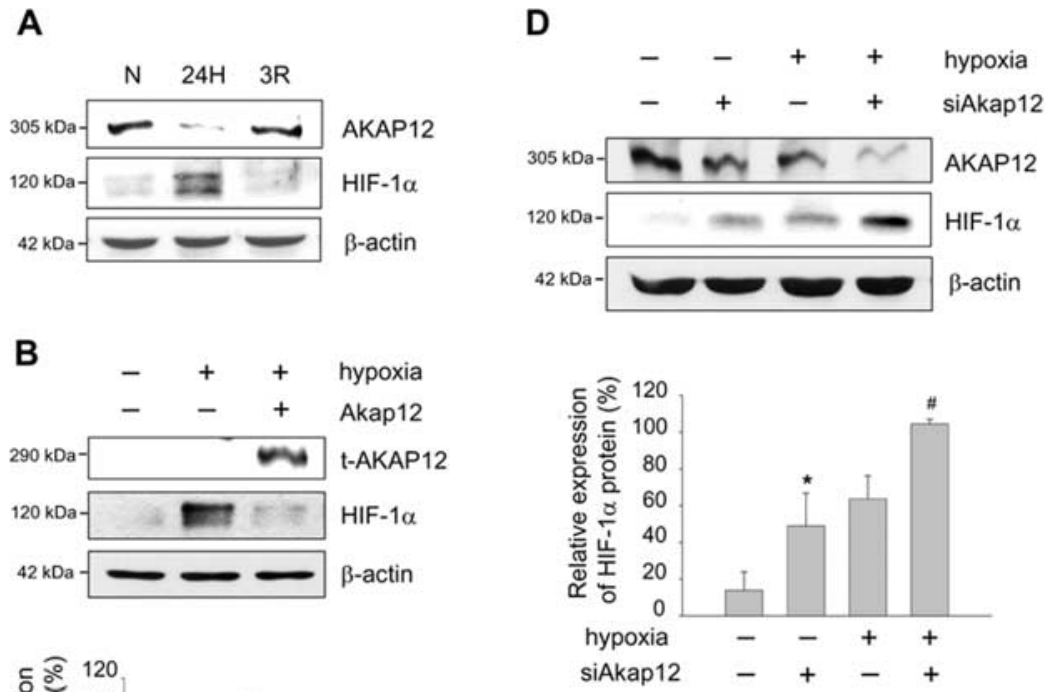

E

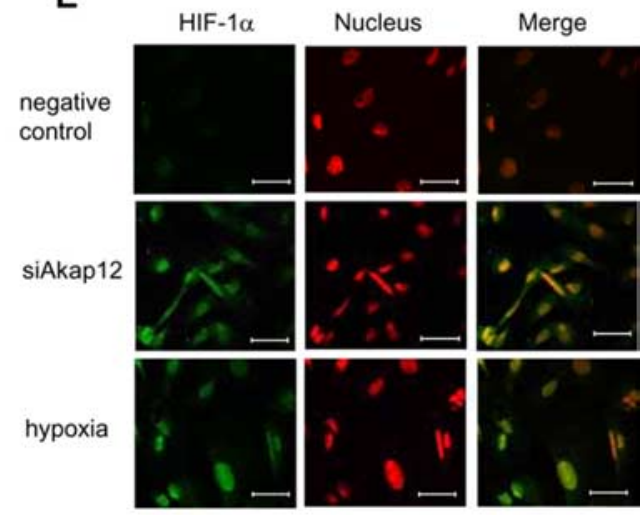

Figure 7. Negative regulation of HIF- $1 \alpha$ by AKAP12. A, Human astrocytes were exposed to $24 \mathrm{~h}$ of normoxia (N) or hypoxia (24H), or $24 \mathrm{~h}$ of hypoxia followed by reoxygenation for $3 \mathrm{~h}$ (3R). Expression of AKAP12 and HIF-1 $\alpha$ was examined by Western blot analysis. $\boldsymbol{B}$, Human astrocytes were transfected with Akap 12 (t-AKAP12), incubated for $12 \mathrm{~h}$, then exposed to $24 \mathrm{~h}$ of normoxia or experiments is shown below. The expression under hypoxia was set to $100 \%$. ${ }^{*} p<0.05$ compared with control in hypoxic exposed to $24 \mathrm{~h}$ of normoxia or hypoxia, and expression of AKAP12 and HIF- $1 \alpha$ was analyzed by Western blot. $\beta$-actin was used examined by immunofluorescence staining. Nuclei were stained with propidium iodide and are seen in red, and colocalization is seen as yellow fluorescence. Scale bar, $50 \mu \mathrm{m}$.

retinal angiogenesis by downregulating HIF-1 $\alpha$ protein (West et al., 2005). Until recently, several posttranslational modifications have been reported to regulate HIF- $1 \alpha$ stability in the presence of oxygen. A critical modification of HIF- $1 \alpha$ involves prolyl hydroxylation, which targets HIF- $1 \alpha$ to the pVHL ubiquitination complex, leading to a rapid proteasomal degradation (Salceda and Caro, 1997; Ivan et al., 2001). In contrast to HIF- $1 \alpha$ protein expression, the level of AKAP12 is increased in reoxygenated astrocytes (Fig. 7A). In our previous study, AKAP12/SSeCKS was decreased by hypoxia, then strongly upregulated by reoxygenation, as accessed by Western blot and RT-PCR (Lee et al., 2003), indicating that AKAP12/SSeCKS expression was tightly regulated, at least at the transcriptional level, in response to oxygen tension. AKAP12 acts as a scaffold for multivalent signaling and 
A

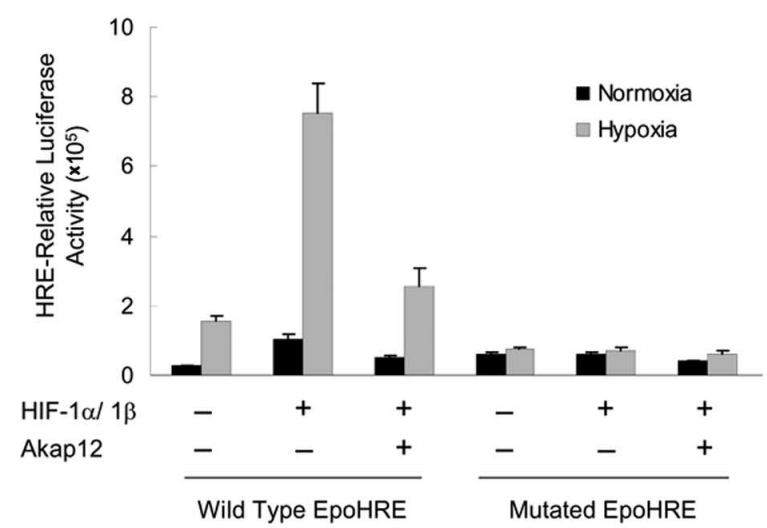

B
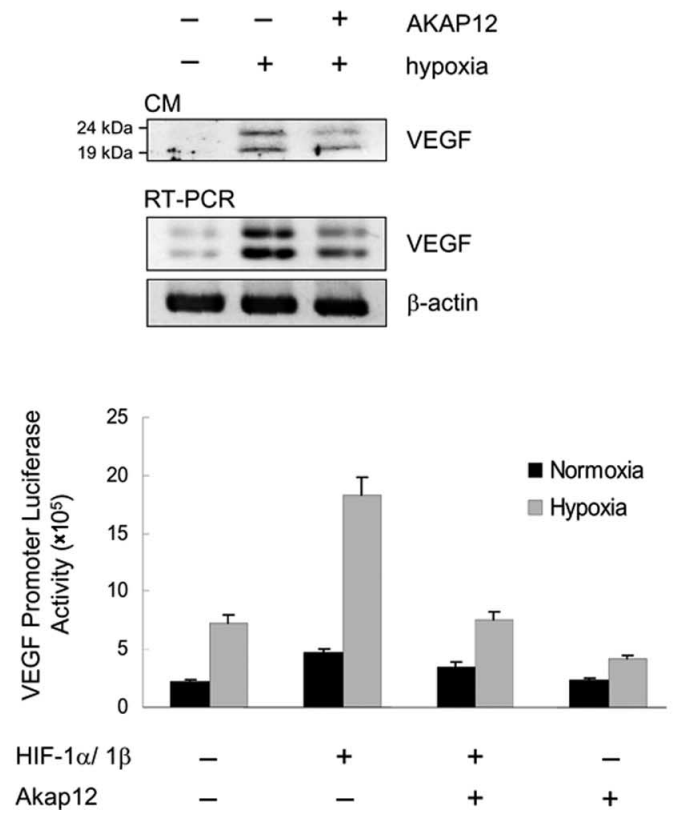

Figure 8. Regulation of transcriptional activities of HIF- $1 \alpha$ and VEGF by AKAP12. A, For analysis of HIF-1 transcriptional activity, cells were transfected with pSV40pro-EpoHRE-Luc (1 $\mu \mathrm{g})$ or mutated EpoHRE-Luc $(1 \mu \mathrm{g})$, pBOS-HIF- $1 \alpha(0.1 \mu \mathrm{g}), \mathrm{pBOS}$-HIF-1 $\beta(0.1 \mu \mathrm{g})$, or empty vector (pEF-BOS, $0.2 \mu \mathrm{g}), \mathrm{pCMV}-\beta$-gal $(0.5 \mu \mathrm{g})$, and $2 \mu \mathrm{g}$ of pcDNA3-Akap12 or pcDNA3, as indicated. Transfected cells were incubated for $12 \mathrm{~h}$, then exposed to $24 \mathrm{~h}$ of normoxia or hypoxia. B, Cells were transfected with Akap12, incubated for $12 \mathrm{~h}$, then exposed to $24 \mathrm{~h}$ of normoxia or hypoxia. VEGF expression was analyzed by Western blot analysis of CM (100 $\mu \mathrm{g}$ total protein) and RT-PCR. For analysis of VEGF transcriptional activity, cells were transfected with pcDNA-Akap 12 or pcDNA $(2 \mu \mathrm{g})$, the VEGF promoter vector pGL3-mVEGF $(1 \mu \mathrm{g})$, pBOS-HIF-1 $\alpha(0.1$ $\mu \mathrm{g})$, pBOS-HIF- $1 \beta(0.1 \mu \mathrm{g})$, or empty vector (pEF-BOS; $0.2 \mu \mathrm{g})$, and pCMV- $\beta$-gal $(0.5 \mu \mathrm{g})$. After transfection, cells were incubated for $12 \mathrm{~h}$ and then exposed to $24 \mathrm{~h}$ normoxia or hypoxia.

associates with PKC, PKA, calmodulin, cyclins, F-actin, and $\beta$-adrenergic receptors, providing a dynamic, reversible platform for signaling (Lin et al., 1996; Gelman, 2002). Recent reports show that hypoxia/aglycemia alters expression and organization of actin cytoskeletal protein, particularly mediated by phosphorylation events by PKC or by calcium-regulated signaling (Park et al., 1999; Brown et al., 2004; Brown and Davis, 2005). PKCinduced phosphorylation of AKAP12 causes it to translocate from cytoskeletal sites to the perinucleus in fibroblasts and mesangial and epithelial cells (Lin et al., 1996; Chapline et al., 1998; Nelson et al., 1999). AKAP12 binding partners are also dynamically recruited or released by these phosphorylation events (Wong and Scott, 2004). Based on these reports, we assume that
A

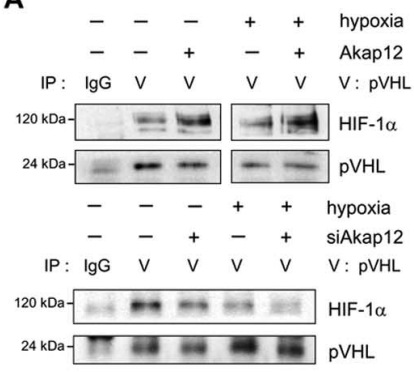

B

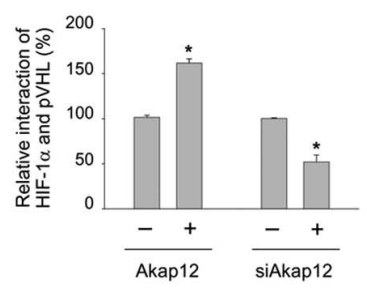

C

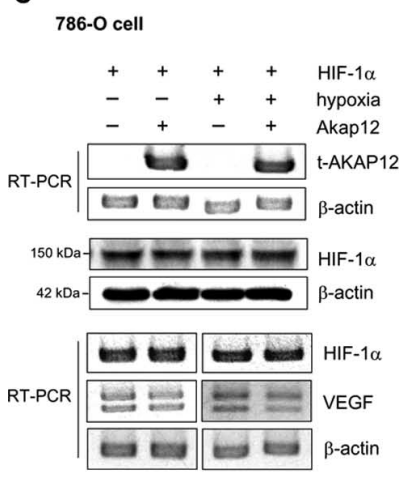

D

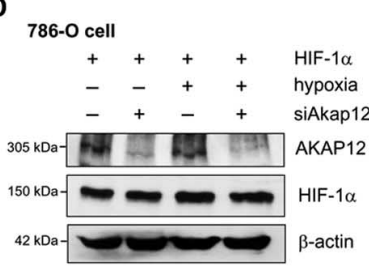

786-O cell /pVHL
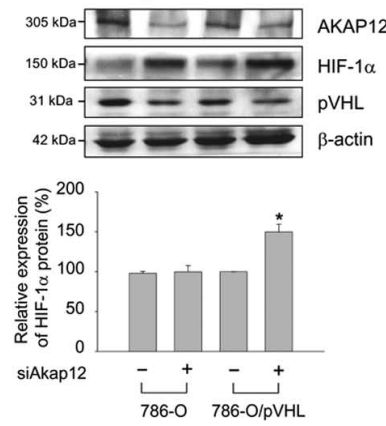

Figure 9. AKAP12 decreases the stability of HIF- $1 \alpha$ by increasing its association with $\mathrm{pVHL}$. $A, B$, Human astrocytes were transfected with AKAP12 or siAkap12, incubated for $12 \mathrm{~h}$, and then exposed to $24 \mathrm{~h}$ of normoxia or hypoxia. Cells were treated with $8 \mu \mathrm{m} \mathrm{MG132} \mathrm{for} 4 \mathrm{~h}$ and then cell extracts were subjected to immunoprecipitation using anti-pVHL antibody. Immunoprecipitates were analyzed by Western blot using anti-HIF-1 $\alpha$ antibody $(\boldsymbol{A})$. The quantification of the immunoblot from three independent experiments is shown $(\boldsymbol{B}) .{ }^{*} p<0.05$ compared with control in normoxic condition. C, 786-0 renal clear cell carcinoma cells were transfected with Akap12 $(1.5 \mu \mathrm{g})$ and green fluorescent protein (GFP)-HIF-1 $\alpha(1.5 \mu \mathrm{g})$. The expression of HIF- $1 \alpha$ was analyzed by Western blot and RT-PCR. D, 786- 0 cells and 786-0 cells expressing pVHL (786- 0 cell/pVHL) were transfected with siAkap12 and GFP-HIF- $1 \alpha(1.5 \mu \mathrm{g})$, incubated for $12 \mathrm{~h}$, then exposed to $24 \mathrm{~h}$ of normoxia or hypoxia, and expression of HIF- $1 \alpha$ and pVHL was analyzed by Western blot. The quantification of the immunoblot from three independent experiments is shown below. ${ }^{*} p<0.05$ compared with control in normoxic condition.

hypoxic signaling may influence the expression or reorganization of AKAP12 by inducing dynamic signal transduction. In this report, we show that AKAP12 is an important negative regulator of HIF- $1 \alpha$ protein. Overexpression of AKAP12 diminished HIF- $1 \alpha$ protein stability (Fig. $7 B$ ), whereas knockdown of AKAP12 by siAkap12 significantly induced HIF- $1 \alpha$ protein in normoxia (Fig. $7 D, E)$. We demonstrated that AKAP12 induces HIF- $1 \alpha$ degradation by upregulating HIF- $1 \alpha$-pVHL and HIF- $1 \alpha$-PHD2 interactions (Figs. 9A, 10A).

Our findings suggest that AKAP12 mediates inner BRB maturation by downregulating HIF-1 $\alpha$ protein level, which leads to an increase in the secretion of Ang1 and a decrease in the secretion of VEGF in human astrocytes. In our previous study, the level of Ang1 was reduced in hypoxic condition and was increased in reoxygenation condition in primary rat astrocyte cells (Song et al., 2002). In this report, we investigated whether HIF- $1 \alpha$ is involved in the regulation of Ang1 expression, and found that HIF- $1 \alpha$ can act as a negative regulator of Ang1 because diminished HIF- $1 \alpha$ level by siHIF- $1 \alpha$ increased the expression of Ang1 in CM (Fig. 6A). Inter- 
A

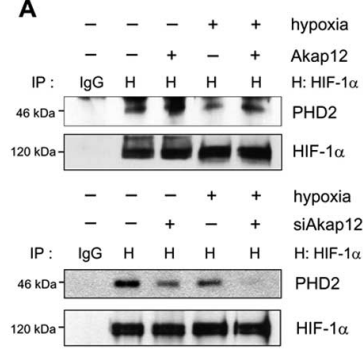

C -++++ hypoxia

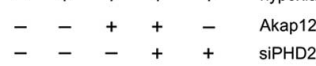

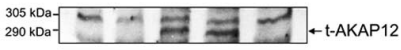

$120 \mathrm{kDa}=\mathrm{HIF-1} \alpha$

${ }_{46 \mathrm{kDa}}-\boldsymbol{C}-\ldots-\cdots$
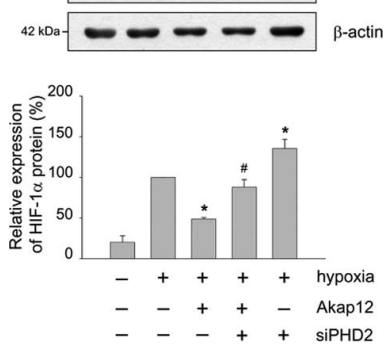

Figure 10. AKAP12 decreases the stability of HIF- $1 \alpha$ by increasing its association with PHD2. A, B, Human astrocytes were transfected with Akap 12 or siAkap12, incubated for $12 \mathrm{~h}$, then exposed to $24 \mathrm{~h}$ of normoxia or hypoxia. Cells were treated with $8 \mu \mathrm{m} \mathrm{MG132}$ for $4 \mathrm{~h}$, then cell extracts were subjected to immunoprecipitation using anti-HIF-1 $\alpha$ antibody. Immunoprecipitates were analyzed by Western blot using anti-PHD2 specific antibody $(\boldsymbol{A})$. The quantification of the immunoblot from three independent experiments is shown $(\boldsymbol{B}) .{ }^{*} p<0.05 \mathrm{com}-$ pared with control in normoxic condition. $\mathbf{C}$, Human astrocytes were cotransfected with rat Akap $12(2 \mu \mathrm{g})$ and siRNA targeting PHD2 (siPHD), incubated for $12 \mathrm{~h}$, then exposed to $24 \mathrm{~h}$ of normoxia or hypoxia. Levels of transfected AKAP12 (t-AKAP12), HIF- $1 \alpha$, and PHD2 were analyzed by Western blot. The quantification of the immunoblot from three independent experiments is shown below. ${ }^{*} p<0.05$ compared with mock-transfected hypoxic condition; ${ }^{\#} p<$ 0.05 compared with Akap12-transfected hypoxic condition. D, HT1080 cells under hypoxic conditions were treated with $300 \mu \mathrm{m}$ of the PHD inhibitors such as Mim and ethyl DHB for $16 \mathrm{~h}$. t-AKAP12 and HIF-1 $\alpha$ expression were analyzed by Western blot.

estingly, the 5'UTR region of human Angl contains three potential reverse HRE (rHRE) regions (DNA consensus 5'-TGCAC-3'). A recent study showed that HIF- $1 \alpha$ acts as a transcriptional repressor of certain genes by direct binding to specific rHREs, HREs on the antisense strand (Narravula and Colgan, 2001). These could provide the possibility of the downregulation of Ang1 level by HIF- $1 \alpha$. Based on this assumption, it will be interesting to explore the mechanisms of how HIF- $1 \alpha$ regulates Ang1 level.

AKAP12 significantly regulates the secretion levels of Ang1 and VEGF (Fig. $4 B, C$ ) more than the intracellular Ang1 and VEGF levels (data not shown) because the BRB formation requires the binding of secreted Ang1 and VEGF to endothelial cell receptors (Millauer et al., 1993; Davis et al., 1996). VEGF is the principal factor involved in retinal angiogenesis (Dvorak et al., 1999; Provis, 2001) and in the breakdown of the BRB (Qaum et al., 2001; Wang et al., 2001; Witmer et al., 2003). However, Ang1 acts in human retinal vessel development, namely, during vessel remodeling, maturation, and stabilization (Thurston et al., 2000; Joussen et al., 2002). Transgenic mice with inducible expression of Ang1 in the retina decreased VEGF-induced leakiness of the vessels (Nambu et al., 2004). Thus, AKAP12 may reciprocally regulate the secretion of Ang1 and VEGF through HIF- $1 \alpha$ in astrocytes during a critical period in human retinal vascular maturation and contribute to $\mathrm{BRB}$ development by upregulating the expression of tight junction proteins ZO-1, ZO-2, claudin-1, claudin-3, claudin-5, and occludin in endothelial cells (Fig. 5A).

In contrast to its expression during inner BRB development, AKAP12 expression was absent in retinoblastoma tissues (Figs. 1, $3 B$ ). Notably, whereas VEGF immunoreactivity in the mature normal retina was negligible (Figs. 1, 2A), it was strongly detected in retinoblastoma tissue (Fig. $3 B$ ). These results corroborate studies showing a marked increase in VEGF expression in eyes bearing intraocular tumors (Stitt et al., 1998). Therefore, the extremely reduced expression of AKAP12 in retinoblastoma may lead to upregulation of HIF- $1 \alpha$ and VEGF, which can then induce the BRB breakdown associated with these tumors.

In conclusion, we show that AKAP12 plays a critical role in mediating important interactions between retinal endothelial cells and astrocytes during human retinal barriergenesis. These observations provide insight into normal retinal barrier development, and the retinal diseases associated with barrier defects, such as retinoblastoma, diabetic retinopathy, and retinopathy of prematurity.

\section{References}

Abbott NJ, Ronnback L, Hansson E (2006) Astrocyte-endothelial interactions at the blood-brain barrier. Nat Rev Neurosci 7:41-53.

Appelhoff RJ, Tian YM, Raval RR, Turley H, Harris AL, Pugh CW, Ratcliffe PJ, Gleadle JM (2004) Differential function of the prolyl hydroxylases PHD1, PHD2, and PHD3 in the regulation of hypoxia-inducible factor. J Biol Chem 279:38458-38465.

Berra E, Benizri E, Ginouves A, Volmat V, Roux D, Pouyssegur J (2003) HIF prolyl-hydroxylase 2 is the key oxygen sensor setting low steady-state levels of HIF-1alpha in normoxia. EMBO J 22:4082-4090.

Brown RC, Davis TP (2005) Hypoxia/aglycemia alters expression of occludin and actin in brain endothelial cells. Biochem Biophys Res Commun 327:1114-1123.

Brown RC, Mark KS, Egleton RD, Davis TP (2004) Protection against hypoxia-induced blood-brain barrier disruption: changes in intracellular calcium. Am J Physiol Cell Physiol 286:C1045-1052.

Chapline C, Cottom J, Tobin H, Hulmes J, Crabb J, Jaken S (1998) A major, transformation-sensitive PKC-binding protein is also a PKC substrate involved in cytoskeletal remodeling. J Biol Chem 273:19482-19489.

Cho CH, Kammerer RA, Lee HJ, Yasunaga K, Kim KT, Choi HH, Kim W, Kim SH, Park SK, Lee GM, Koh GY (2004) Designed angiopoietin-1 variant, COMP-Ang1, protects against radiation-induced endothelial cell apoptosis. Proc Natl Acad Sci USA 101:5553-5558.

Davis S, Aldrich TH, Jones PF, Acheson A, Compton DL, Jain V, Ryan TE, Bruno J, Radziejewski C, Maisonpierre PC, Yancopoulos GD (1996) Isolation of angiopoietin-1, a ligand for the TIE2 receptor, by secretiontrap expression cloning. Cell 87:1161-1169.

Dvorak HF, Nagy JA, Feng D, Brown LF, Dvorak AM (1999) Vascular permeability factor/vascular endothelial growth factor and the significance of microvascular hyperpermeability in angiogenesis. Curr Top Microbiol Immunol 237:97-132.

Ema M, Taya S, Yokotani N, Sogawa K, Matsuda Y, Fujii-Kuriyama Y (1997) A novel bHLH-PAS factor with close sequence similarity to hypoxiainducible factor 1alpha regulates the VEGF expression and is potentially involved in lung and vascular development. Proc Natl Acad Sci USA 94:4273-4278.

Engelhardt B (2003) Development of the blood-brain barrier. Cell Tissue Res 314:119-129.

Epstein AC, Gleadle JM, McNeill LA, Hewitson KS, O’Rourke J, Mole DR, Mukherji M, Metzen E, Wilson MI, Dhanda A, Tian YM, Masson N, Hamilton DL, Jaakkola P, Barstead R, Hodgkin J, Maxwell PH, Pugh CW, Schofield CJ, Ratcliffe PJ (2001) C. elegans EGL-9 and mammalian homologs define a family of dioxygenases that regulate HIF by prolyl hydroxylation. Cell 107:43-54.

Furuse M, Itoh M, Hirase T, Nagafuchi A, Yonemura S, Tsukita S, Tsukita S (1994) Direct association of occludin with ZO-1 and its possible involvement in the localization of occludin at tight junctions. J Cell Biol 127:1617-1626. 
Gelman IH (2002) The role of SSeCKS/gravin/AKAP12 scaffolding proteins in the spaciotemporal control of signaling pathways in oncogenesis and development. Front Biosci 7:d1782-d1797.

Gelman IH, Tombler E, Vargas Jr J (2000) A role for SSeCKS, a major protein kinase $\mathrm{C}$ substrate with tumour suppressor activity, in cytoskeletal architecture, formation of migratory processes, and cell migration during embryogenesis. Histochem J 32:13-26.

Hori S, Ohtsuki S, Hosoya K, Nakashima E, Terasaki T (2004) A pericytederived angiopoietin-1 multimeric complex induces occludin gene expression in brain capillary endothelial cells through Tie- 2 activation in vitro. J Neurochem 89:503-513.

Ikeda E, Achen MG, Breier G, Risau W (1995) Hypoxia-induced transcriptional activation and increased mRNA stability of vascular endothelial growth factor in C6 glioma cells. J Biol Chem 270:19761-19766.

Ivan M, Kondo K, Yang H, Kim W, Valiando J, Ohh M, Salic A, Asara JM, Lane WS, Kaelin Jr WG (2001) HIFalpha targeted for VHL-mediated destruction by proline hydroxylation: implications for $\mathrm{O} 2$ sensing. Science 292:464-468.

Jaakkola P, Mole DR, Tian YM, Wilson MI, Gielbert J, Gaskell SJ, Kriegsheim A, Hebestreit HF, Mukherji M, Schofield CJ, Maxwell PH, Pugh CW, Ratcliffe PJ (2001) Targeting of HIF-alpha to the von Hippel-Lindau ubiquitylation complex by O2-regulated prolyl hydroxylation. Science 292:468-472.

Jain S, Maltepe E, Lu MM, Simon C, Bradfield CA (1998) Expression of ARNT, ARNT2, HIF1 alpha, HIF2 alpha and Ah receptor mRNAs in the developing mouse. Mech Dev 73:117-123.

Joussen AM, Poulaki V, Tsujikawa A, Qin W, Qaum T, Xu Q, Moromizato Y, Bursell SE, Wiegand SJ, Rudge J, Ioffe E, Yancopoulos GD, Adamis AP (2002) Suppression of diabetic retinopathy with angiopoietin-1. Am J Pathol 160:1683-1693.

Kivela T, Tarkkanen A, Virtanen I (1986) Intermediate filaments in the human retina and retinoblastoma. An immunohistochemical study of vimentin, glial fibrillary acidic protein, and neurofilaments. Invest Ophthalmol Vis Sci 27:1075-1084.

Lee MS, Moon EJ, Lee SW, Kim MS, Kim KW, Kim YJ (2001a) Angiogenic activity of pyruvic acid in in vivo and in vitro angiogenesis models. Cancer Res 61:3290-3293.

Lee SW, Kim WJ, Choi YK, Song HS, Son MJ, Gelman IH, Kim YJ, Kim KW (2003) SSeCKS regulates angiogenesis and tight junction formation in blood-brain barrier. Nat Med 9:900-906.

Lee YM, Jeong CH, Koo SY, Son MJ, Song HS, Bae SK, Raleigh JA, Chung HY, Yoo MA, Kim KW (2001b) Determination of hypoxic region by hypoxia marker in developing mouse embryos in vivo: a possible signal for vessel development. Dev Dyn 220:175-186.

Lin X, Tombler E, Nelson PJ, Ross M, Gelman IH (1996) A novel src- and ras-suppressed protein kinase $\mathrm{C}$ substrate associated with cytoskeletal architecture. J Biol Chem 271:28430-28438.

Liu Y, Gao L, Gelman IH (2006) SSeCKS/Gravin/AKAP12 attenuates expression of proliferative and angiogenic genes during suppression of $\mathrm{v}$-Src-induced oncogenesis. BMC Cancer 6:105.

Madan A, Varma S, Cohen HJ (2002) Developmental stage-specific expression of the alpha and beta subunits of the HIF-1 protein in the mouse and human fetus. Mol Genet Metab 75:244-249.

Maxwell PH, Dachs GU, Gleadle JM, Nicholls LG, Harris AL, Stratford IJ, Hankinson O, Pugh CW, Ratcliffe PJ (1997) Hypoxia-inducible factor-1 modulates gene expression in solid tumors and influences both angiogenesis and tumor growth. Proc Natl Acad Sci USA 94:8104-8109.

Maxwell PH, Wiesener MS, Chang GW, Clifford SC, Vaux EC, Cockman ME, Wykoff CC, Pugh CW, Maher ER, Ratcliffe PJ (1999) The tumour suppressor protein VHL targets hypoxia-inducible factors for oxygendependent proteolysis. Nature 399:271-275.

Millauer B, Wizigmann-Voos S, Schnurch H, Martinez R, Moller NP, Risau W, Ullrich A (1993) High affinity VEGF binding and developmental expression suggest Flk-1 as a major regulator of vasculogenesis and angiogenesis. Cell 72:835-846.

Moon EJ, Jeong CH, Jeong JW, Kim KR, Yu DY, Murakami S, Kim CW, Kim KW (2004) Hepatitis B virus X protein induces angiogenesis by stabilizing hypoxia-inducible factor-1alpha. FASEB J 18:382-384.

Morcos Y, Hosie MJ, Bauer HC, Chan-Ling T (2001) Immunolocalization of occludin and claudin-1 to tight junctions in intact CNS vessels of mammalian retina. J Neurocytol 30:107-123.
Nambu H, Nambu R, Oshima Y, Hackett SF, Okoye G, Wiegand S, Yancopoulos G, Zack DJ, Campochiaro PA (2004) Angiopoietin 1 inhibits ocular neovascularization and breakdown of the blood-retinal barrier. Gene Ther 11:865-873.

Narravula S, Colgan SP (2001) Hypoxia-inducible factor 1-mediated inhibition of peroxisome proliferator-activated receptor alpha expression during hypoxia. J Immunol 166:7543-7548.

Nelson PJ, Moissoglu K, Vargas Jr J, Klotman PE, Gelman IH (1999) Involvement of the protein kinase C substrate, SSeCKS, in the actin-based stellate morphology of mesangial cells. J Cell Sci 112:361-370.

Nitta T, Hata M, Gotoh S, Seo Y, Sasaki H, Hashimoto N, Furuse M, Tsukita S (2003) Size-selective loosening of the blood-brain barrier in claudin5-deficient mice. J Cell Biol 161:653-660.

Park JH, Okayama N, Gute D, Krsmanovic A, Battarbee H, Alexander JS (1999) Hypoxia/aglycemia increases endothelial permeability: role of second messengers and cytoskeleton. Am J Physiol 277:C1066-C1074.

Provis JM (2001) Development of the primate retinal vasculature. Prog Retin Eye Res 20:799-821.

Qaum T, Xu Q, Joussen AM, Clemens MW, Qin W, Miyamoto K, Hassessian H, Wiegand SJ, Rudge J, Yancopoulos GD, Adamis AP (2001) VEGFinitiated blood-retinal barrier breakdown in early diabetes. Invest Ophthalmol Vis Sci 42:2408-2413.

Salceda S, Caro J (1997) Hypoxia-inducible factor lalpha (HIF-1alpha) protein is rapidly degraded by the ubiquitin-proteasome system under normoxic conditions. Its stabilization by hypoxia depends on redoxinduced changes. J Biol Chem 272:22642-22647.

Sambrook J, Russell D (2001) Molecular Cloning: a laboratory manuel. New York: Cold Spring Harbor.

Sandercoe TM, Geller SF, Hendrickson AE, Stone J, Provis JM (2003) VEGF expression by ganglion cells in central retina before formation of the foveal depression in monkey retina: evidence of developmental hypoxia. J Comp Neurol 462:42-54.

Semenza GL (2003) Targeting HIF-1 for cancer therapy. Nat Rev Cancer 3:721-732.

Song HS, Son MJ, Lee YM, Kim WJ, Lee SW, Kim CW, Kim KW (2002) Oxygen tension regulates the maturation of the blood-brain barrier. Biochem Biophys Res Commun 290:325-331.

Stanness KA, Guatteo E, Janigro D (1996) A dynamic model of the bloodbrain barrier "in vitro". Neurotoxicology 17:481-496.

Stitt AW, Simpson DA, Boocock C, Gardiner TA, Murphy GM, Archer DB (1998) Expression of vascular endothelial growth factor (VEGF) and its receptors is regulated in eyes with intra-ocular tumours. J Pathol 186:306-312.

Stone J, Itin A, Alon T, Pe'er J, Gnessin H, Chan-Ling T, Keshet E (1995) Development of retinal vasculature is mediated by hypoxia-induced vascular endothelial growth factor (VEGF) expression by neuroglia. J Neurosci 15:4738-4747.

Thurston G, Rudge JS, Ioffe E, Zhou H, Ross L, Croll SD, Glazer N, Holash J, McDonald DM, Yancopoulos GD (2000) Angiopoietin-1 protects the adult vasculature against plasma leakage. Nat Med 6:460-463.

Wang GL, Jiang BH, Rue EA, Semenza GL (1995) Hypoxia-inducible factor 1 is a basic-helix-loop-helix-PAS heterodimer regulated by cellular $\mathrm{O} 2$ tension. Proc Natl Acad Sci USA 92:5510-5514.

Wang W, Dentler WL, Borchardt RT (2001) VEGF increases BMEC monolayer permeability by affecting occludin expression and tight junction assembly. Am J Physiol Heart Circ Physiol 280:H434-H440.

Werdich XQ, McCollum GW, Rajaratnam VS, Penn JS (2004) Variable oxygen and retinal VEGF levels: correlation with incidence and severity of pathology in a rat model of oxygen-induced retinopathy. Exp Eye Res 79:623-630.

West H, Richardson WD, Fruttiger M (2005) Stabilization of the retinal vascular network by reciprocal feedback between blood vessels and astrocytes. Development 132:1855-1862.

Witmer AN, Vrensen GF, Van Noorden CJ, Schlingemann RO (2003) Vascular endothelial growth factors and angiogenesis in eye disease. Prog Retin Eye Res 22:1-29.

Wong W, Scott JD (2004) AKAP signalling complexes: focal points in space and time. Nat Rev Mol Cell Biol 5:959-970.

Xia W, Unger P, Miller L, Nelson J, Gelman IH (2001) The Src-suppressed C kinase substrate, SSeCKS, is a potential metastasis inhibitor in prostate cancer. Cancer Res 61:5644-5651. 